\title{
La vida como narración (Aranguren y Ricoeur)
}

\author{
Life as Narrative (Aranguren and Ricoeur)
}

CARLOS GÓMEZ*

Resumen: Tras la introducción (1), en la que se aborda el teatro como gran metáfora de la vida, se tratan, al hilo de recientes reflexiones de $\mathrm{P}$. Ricoeur (2), las relaciones entre relato y vida, para plantearnos a continuación (3), de la mano de la categoría kierkegaardiana de "instante" retomada por J. L. Aranguren, su posible correspondencia con otros géneros literarios y fundamentalmente con la poesía. Finalizamos (4) con algunas propuestas antropológicas desde la perspectiva de la vida como texto y la comprensión de sí.

Palabras clave: Ricoeur; Aranguren; identidad narrativa; géneros literarios; hermenéutica de sí.

\begin{abstract}
After the introduction (1), which deals with theater as great metaphor for life, the relationship between story and life, following P. Ricoeur's recent reflections, is discussed (2), considering its possible correspondence with other literary genres and, mainly, poetry, with the Kierkegaardian category of the "instant" as taken up by J. L. Aranguren (3). We shall finish (4) with some anthropological proposals from the perspective of life as a text and selfcomprehension.
\end{abstract}

Keywords: Ricoeur; Aranguren; narrative identity; literary genres; hermeneutics of the self

\section{Introducción}

Las relaciones entre Filosofía y Literatura pueden abordarse desde muchos ángulos, según pone de manifiesto una compleja gama argumental que discurre desde los grandes textos platónicos a reflexiones como la realizada por Paul Ricoeur en La metáfora viva (Ricoeur, 2001)1. La reflexión sobre las mismas se suele realizar partiendo prevalentemente

Fecha de recepción: 18/01/2015. Fecha de aceptación: 13/04/2015.

* UNED, Catedrático de Filosofía Moral y Política, cgomez@fsof.uned.es. Líneas de investigación: relaciones de la Ética con la Teoría Psicoanalítica ("La réalité et l'illusion. Cervantès chez Freud”, Oedipe le Salon, Oedipe à Alcala. Le désir du psychanalyste à l'épreuve de don Quichotte, París, Éditions des Crépuscules, 41-68, 2012) y con la Filosofía de la Religión (“Religión, política y metafísica en Leszek Kolakowski”, en J. San Martín y J. J. Sánchez (eds.), Pensando la religión. Homenaje a Manuel Fraijó, Madrid, ed. Trotta, pp. 312-324, 2013).

1 De esa multiplicidad de enfoques dan buena cuenta dos recientes cursos celebrados al respecto en nuestro país en julio de 2014, el primero de ellos dirigido por J. M. Marinas (con ponencias, entre otros de J. M ${ }^{\mathrm{a}}$ González y C. Thiebaut) y el segundo por F. J. Martínez (con ponencias, entre otros, de F. Bayón y F. R. de la Flor), y que tuvieron lugar en El Escorial y Ávila, en el marco de la Universidad Complutense y de la UNED, respectivamente. También E. Trías consideró en su día la filosofía como "literatura del conocimiento" (Trías, 2002). El aludido papel de la metáfora, aplicado al campo de la Filosofía Política, ha sido analizado, entre nosotros, por José M Ma González en Metáforas del poder (González, 1998) y con posterioridad en La diosa Fortuna. Metamorfosis de una metáfora política, (González, 2006). Entre muchas otras referencias el lector 
de uno de los campos, por lo demás difíciles de acotar, de la Literatura o la Filosofía. Pero también hay quienes se desempeñan en ambos con notable lucidez, como es el caso de Juan Mayorga, conocido ante todo por su actividad literaria -debido a la cual, y además de estar traducido a más de veinte idiomas, en 2014 le fue concedido el Premio Nacional de Literatura, en su modalidad de Literatura dramática, por su versión teatral de El libro de la vida de Teresa de Ávila-, pero que asimismo es doctor en Filosofía ${ }^{2}$.

El libro de la vida - un ejemplo por antonomasia de la vida como narración- es una obra desconcertante y peligrosa, si uno se la toma en serio y no simplemente se acerca a ella con el prejuicio de descubrir determinadas patologías. Con independencia de las que en la santa se pudieran registrar, uno de los problemas planteados por ese texto, como por el de los místicos en general, es cómo con esas posibles patologías e incluso a pesar de ellas, se alzan sobre las mismas hasta el punto de que, mientras una fantasía histérica, una obsesión, un delirio psicótico permanecen mudos y opacos, como en la oscuridad de un sueño privado y nocturno, esas obras logran una pública lucidez, capaz de alumbrar durante siglos al resto de los hombres y ayudarnos a decir en qué consiste nuestra común humanidad. Por lo que a Teresa de Ávila se refiere, recuerdo a este respecto el comentario de un crítico inglés, al que, con otro motivo, trajo a colación en su día Fernando Savater: "Siempre que se tiene un libro suyo en las manos se siente la compañía de alguien real” (Savater, 1990).

Pero, sin insistir más en estas observaciones iniciales, creo que de este modo hemos entrado de lleno en el tema, como si al tocar un instrumento atacáramos directamente la cuerda, por retomar una conocida expresión de Pau Casals. Es preciso, sin embargo, que refrenemos ahora el paso para plantearnos metódicamente la cuestión anunciada en el título de este artículo.

Lo quiero hacer girar en torno a las aportaciones de dos filósofos contemporáneos, Aranguren y Ricoeur. Además de los textos a los que fundamentalmente me voy a referir, ambos tienen una dilatada trayectoria en torno a esas cuestiones fronterizas de "Filosofía y Literatura". Piénsese, por ejemplo, en los tres volúmenes de Tiempo y narración de Paul Ricoeur (Ricoeur, 1995-1996) o en el libro Estudios literarios (Aranguren, 1993 y 19941996) que agrupa las muchas ocasiones en que José Luis Aranguren se ocupó de las mismas. Y aunque en el primer tramo de esta exposición me serviré ante todo del texto de Ricoeur "La vida: un relato en busca de narrador", aparecido en el volumen 1 de sus escritos póstumos (Ricoeur, 2009), veremos cómo, en muchos casos, las formulaciones de Aranguren se

puede orientarse a través del $\mathrm{n}^{\circ} 11$ de Isegoría (1995), consagrado específicamente a las relaciones entre Filosofía y Literatura -con textos, entre otros, de M. C. Nussbaum, C. Thiebaut (Thiebaut, 1995) y J. M ${ }^{\mathrm{a}}$ Valverde-); también la obra de $\mathrm{M}^{\mathrm{a}}$ Teresa López de la Vieja aborda la cuestión desde el punto de vista de la Ética (López de la Vieja, 2003) y más tarde de la Bioética (López de la Vieja, 2013). Asimismo las Conferencias Aranguren celebradas en mayo de 2004 en el marco de la Residencia de Estudiantes de Madrid se centraron en tales relaciones, desarrolladas en esa ocasión por Fernando Savater.

2 Especialista en W. Benjamin, realizó su tesis doctoral en la UNED, bajo la dirección de M. Reyes Mate. Mayorga ha tenido la audacia de llevar ese libro al teatro (La lengua en pedazos, Mayorga 2013 y 2014), cosa nada fácil de hacer y sin embargo muy bien lograda, como el diálogo entre una monja rebelde y un inquisidor. No está de más recordarlo, ahora que nos encontramos en la celebración del V Centenario del nacimiento de Teresa de Ávila, para ayudar a rescatar su figura de la unilateral utilización que de la misma hizo el nacionalcatolicismo, labor a la cual obras como las del propio Mayorga o la del gran hispanista Joseph Pérez, Teresa de Ávila y la España de su tiempo (Pérez, 2007) han desde luego de contribuir. 
encuentran cercanas, sin que por las fechas de publicación se pueda pensar en una directa influencia. Pero, además de su interés en sí, no quiero dejar de recoger sus aportaciones, dada una cierta tendencia entre los españoles a minusvalorar lo que producimos.

$\mathrm{Y}$, sin más preámbulo, para introducirnos en el tema podemos servirnos del breve texto de Aranguren "El teatro y la vida" (Aranguren, 1996 y Gómez, 2010a), que nos puede poner sobre la pista de algunas de las cuestiones que hemos de tratar.

A su entender, en efecto, el teatro se ofrece, junto con el sueño, como la gran metáfora de la vida. En ambos se trata ante todo de escenas -el cuidado por la figurabilidad al que se refería Freud al hablar de la elaboración onírica (Freud, 1972a; Gómez, 2002b y 2010b) - en la que diversos personajes representan distintos papeles, en cuyo desempeño se les supone libres, pues aunque dependen del autor, gozan, hasta cierto punto al menos, de vida propia, de modo que ha llegado a hablarse, como lo hizo Pirandello, de Seis personajes en busca de autor (Pirandello, 1999). Libertad de los personajes respecto al autor dramático que puede convertirse en metáfora de la nuestra misma respecto al posible Autor de la vida: esa polémica -la llamada polémica De auxiliis- desató diversas versiones y argumentos en nuestro Siglo de Oro entre dominicos, partidarios de Domingo Báñez, y jesuitas o molinistas, partidarios de Luis de Molina, a propósito de la posible conjugación entre la gracia y el libre albedrío; se difundió incluso en representaciones teatrales, como por ejemplo, El condenado por desconfiado de Tirso de Molina (Tirso de Molina, 2008), $\mathrm{y}$, con todas las trasposiciones que se quiera a nuestro mundo secularizado, nos puede seguir dando que pensar.

Representación teatral como metáfora de la vida hasta que, después de la última escena, cae el telón y, como al parecer Beethoven en sus últimos momentos, podemos decir: Plaudite, amici, comedia finita est, "Aplaudid, amigos, la representación ha terminado". Y es en ese final cuando preguntamos si los personajes en su papel nos parecían auténticos o no, como en la vida podemos preguntar de alguien si actúa con veracidad. Cuestión difícil de responder, y a la que, como observó Habermas -que hacía de la veracidad una de las cuatro pretensiones de validez del habla, junto a la inteligibilidad, la verdad y la corrección (Habermas, 1985; Gómez, 1995)-, sólo se puede dar una respuesta indirecta en función del conjunto de la vida: alguien, en sus actitudes, resoluciones o propuestas, nos parece veraz si el contexto general de su vida así permite pensarlo. Como también nos podemos plantear, al finalizar y dejar de estar absorbidos por lo que sucede en la escena, si aquello que parecía tener carácter real, lo era verdaderamente o no habrá sido sino un sueño, ¿soñado por quién? Lo retomaremos.

\section{Relato y vida}

Pero el teatro es sólo un caso de narración, en el sentido amplio del término, junto al que cabe agregar otros más estrictamente narrativos como la epopeya o la novela, por no hablar del cine que cuenta con medios de expresión propios. Y ya que se trata de ver las similitudes y diferencias entre la narración y la vida, podemos, para seguir ahora a Ricoeur, partir de un contraste que más tarde irá difuminándose, aunque sin hacer desparecer todas las diferencias. Es el que se puede manifestar en la proposición: "Las historias son contadas y no vividas, la vida es vivida y no contada". 
Para paliar ese contraste, Ricoeur se sirve en primer lugar del concepto de la Poética de Aristóteles (Aristóteles, 1974) de "puesta en intriga", que se dice en griego mythos, tanto en el sentido de fábula o historia imaginaria como en el de intriga o historia bien construida (Cf. asimismo Ricoeur, 1995-1996, I, cap. 2, donde la expresión mise en intrigue se traduce por "construcción de la trama"3). La puesta en intriga supone una síntesis entre la multiplicidad de los acontecimientos y la completud de una historia, que es más que la simple enumeración de los incidentes que en ella van desfilando, al organizar en un conjunto elementos heterogéneos. Se trata, pues de una concordia discors, donde los elementos concordantes y discordantes han de coexistir, si bien los primeros han de alcanzar algún tipo de primacía si queremos hablar de "una historia" y su comprensión. Pero, para poder seguir una historia, la sucesión discreta y teóricamente indefinida de incidentes ha de culminar gracias a una configuración, de manera que componer una historia podría definirse como extraer una configuración de una sucesión. La intriga media, pues, entre la multiplicidad de los acontecimientos y la unidad de la historia, entre la sucesión y la configuración.

Si revisamos desde este punto de vista, la paradoja con la que comenzábamos (las historias se cuentan, la vida es vivida), empezando por el lado del relato, de la ficción, para ver cómo conduce hacia la vida, podemos señalar que la composición de una historia sólo concluye en el lector o en el espectador y por eso su sentido o significación brota de la intersección del mundo del texto y del mundo del lector. Si no lo encerramos en un análisis estructural tomado de la lingüística, un texto, desde el punto de vista hermenéutico, supone una mediación entre el hombre y el mundo (referencialidad), entre el hombre y el hombre (comunicabilidad) y entre el hombre y él mismo (comprensión de sí), por lo que el problema hermenéutico empieza donde la lingüística se detiene: por así decirlo, la hermenéutica se mantiene en la bisagra entre la configuración (interna) de la obra y la refiguración (externa) de la vida, que permite la dinámica de transfiguración de la obra, debido a que la puesta en intriga es la acción común del texto y del lector. Seguir un relato es reactualizar el acto configurante que le da forma y que abre un horizonte de experiencias posibles, un mundo en el que sería posible habitar, de forma que aunque las historias se cuentan, también se viven imaginariamente.

Si lo dicho nos permite transitar de algún modo del relato a la vida, también podemos, a la inversa, tratar de ir de la vida al relato, cuestionando ahora de nuevo, desde este punto de vista, la falsa evidencia de la que partíamos y según la cual la vida se vive y no se cuenta. Y para ello, habría que destacar ante todo la capacidad prenarrativa de la vida. En efecto, la vida humana difiere de la animal por su inteligibilidad narrativa. La vida es sólo un fenómeno meramente biológico en la medida en que no ha sido interpretada, interpretación en la que la ficción juega un papel mediador considerable.

Ese carácter se ve reforzado al reparar en la estructura misma del actuar y el padecer humanos. Comprendemos lo que es una acción gracias a nuestra competencia para utilizar significativamente las expresiones de las lenguas naturales que permiten distinguir la acción del simple movimiento (proyecto, fin, medio, circunstancias...) y que se pueden englobar en la red de la semántica de la acción (Ricoeur, 1988). Por otra parte, si la acción puede ser contada es porque ya está articulada en signos y reglas, simbólicamente mediada con lo

3 Sobre estos problemas de traducción cf. Martín Diez Fischer, 2014. 
que podría llamarse un simbolismo implícito o inmanente, que constituye un contexto de descripción para acciones particulares (así, un mismo gesto se puede interpretar de forma distinta según el contexto y las convenciones simbólicas), de forma que el simbolismo confiere a la acción una primera legibilidad y hace de ella casi un texto.

Y, sobre todo, el relato puede apoyarse en la vida debido a la cualidad prenarrativa de la vida misma, que viene a ser una historia en estado naciente. Claro que esto podría llevar a pensar que nos movemos en un círculo vicioso, pues para defender que la vida se acerca al relato hablamos de la cualidad narrativa de la vida y de su mediación simbólica. Para conjurarlo se pueden aducir una serie de situaciones cotidianas en las que no cabe achacar la narratividad virtual a la posible proyección de la literatura sobre la vida, sino que constituye una auténtica exigencia de relato, como cuando nos referimos a una serie de acontecimientos diciendo cosas como "esta historia merecería ser contada" (luego aún no lo ha sido, más bien se trata -por paradójica que la expresión pueda parecer- de "historias no contadas todavía", y lo que destacamos es que esos acontecimientos contienen una prenarratividad que puede llegar a formalizarse). Pero, además, es posible señalar también situaciones menos habituales, pero no por ello menos importantes o significativas desde el punto de vista que estamos considerando.

Una de ellas proviene del mundo del psicoanálisis. El paciente que se dirige al psicoanalista lo hace siempre motivado por la presión del síntoma (y, quizá además, en ocasiones, por interés intelectual). Pero lo que lleva, o al menos de lo que habla, no es todo su pasado, sino aquellos episodios que le parecen significativos u otros que puedan ir surgiendo, esto es, briznas de historias, lapsus, sueños, historias no contadas y reprimidas (en el sentido psicoanalítico de la represión, Verdrängung) que ahora quizá puedan llegar a contarse o contarse de un modo nuevo, tomando esas historias por constitutivas de su identidad personal. Es la búsqueda de respuestas al interrogante sobre la propia identidad la que permite la continuidad entre la historia potencial o virtual y la historia expresa que responsablemente se asume.

Si del psicoanálisis pasamos al mundo judicial, también en éste se trata en muchas ocasiones de comprender a un inculpado desentrañando la maraña de intrigas en las que se encuentra o ha sido enredado. Esa maraña es entonces algo así como la prehistoria de la historia finalmente contada que emerge de aquel trasfondo. Desde esta perspectiva, el hombre puede ser comprendido como un ser enmarañado en historias y contar como un proceso secundario sobre ese nuestro "ser enmarañado en historias", de modo que contar y seguir una historia no es sino la continuación de esas historias no dichas.

Esto le permite a Ricoeur defender el concepto de identidad narrativa, pues lo que llamamos subjetividad no es ni una serie incoherente de acontecimientos ni una sustancialidad inmutable, sino que, conforme al juego de sedimentación e innovación, nos interpretamos a la luz de relatos que nuestra cultura nos propone y aprendemos a transformarnos en el narrador de nuestra propia vida (en la que resonarán muchas otras voces), sin que por eso nos trasformemos completamente en el autor de nuestra propia vida, en la que, por mucho que nos adueñemos de ella, las condiciones fundamentales se nos escapan: para empezar el hecho mismo de vivir con el que nos encontramos, pero también el aquí y el ahora, en esta sociedad y en esta época, en determinada familia y circunstancias, y abocados a un fin incierto que no podemos nunca por completo decidir. 
Y ésa es la diferencia entre la vida y la ficción, en la cual el narrador es el autor de toda la historia, y lo que hace que, a pesar de todas las similitudes, persista una diferencia infranqueable, por la que al cabo se puede ver el momento de verdad de la afirmación de partida (la vida es vivida y la historia es contada), aun cuando dicha diferencia ha quedado, como hemos visto, parcialmente abolida al poder aplicarnos a nosotros mismos tramas que recibimos de nuestra cultura y sobre las que cabe ensayar diferentes roles a través de variaciones imaginativas. Por eso podía Ortega decir que "el hombre no es cosa ninguna, sino un drama", de modo que cada cual tiene que ser "novelista de sí mismo, original o plagiario", puesto que "el hombre no tiene naturaleza, sino que tiene... historia" (Ortega, 1970 , pp. 36, 39 y 51)

La vida que nos es dada no nos es dada hecha, sino que necesitamos hacérnosla nosotros, cada cual la suya. La vida es quehacer. Y lo más grave de estos quehaceres en que la vida consiste no es que sea preciso hacerlos, sino, en cierto modo, lo contrario -quiero decir que nos encontramos siempre forzados a hacer algo, pero no nos encontramos nunca estrictamente forzados a hacer algo determinado, que no nos es impuesto este o el otro quehacer, como le es impuesta al astro su trayectoria o a la piedra la gravitación. Antes que hacer algo, tiene cada hombre que decidir, por su cuenta y riesgo, lo que va a hacer (Ibíd., pp. 3-4).

Lo que llamamos el sujeto no es nunca algo dado desde el principio, a no ser reducido al yo narcisista o al yo exaltado del Cogito cartesiano, que a Ricoeur no le parece sino un atajo: es preciso quedar mediado por los otros y los documentos sedimentados de la cultura para poder realmente acceder a sí. Es la tesis fundamental de su gran obra Sí mismo como otro (Ricoeur, 1996), en donde se opondrá tanto al Cogito exaltado cartesiano como al Cogito humillado de la postmodernidad, defendiendo el concepto de identidad narrativa aquí esbozado, a través de la diferencia entre la mismidad, como sinónimo de la identidad-idem, y la ipseidad por referencia a la identidad $i p s e^{4}$. De este modo, en lugar de un yo abortado y clausurado en sí mismo nos abrimos a un yo instruido por los símbolos culturales y entre ellos los relatos literarios que nos confieren una unidad no sustancial sino narrativa.

\section{La vida en un instante}

Pero si la narración supone distensión (o esa mediación entre multiplicidad y unidad, sucesión y configuración, de la que hablábamos) podríamos preguntarnos también: ¿no sería posible, en algunas experiencias al menos, ceñir toda la vida, tenerla ante nosotros como si se nos ofreciera entera, junta y apretada, en un instante?

4 Cf. A. Pérez Quintana, "Hombre capaz: Reconocimiento y justicia en la ética de Paul Ricoeur”, en T. Oñate, ed., Centenario P. Riocuer. Tiempo, dolor, justicia” (en prensa). Los capítulos centrales del libro constituyen la "Ética" de Ricoeur, de la que él mismo ofreció un resumen en su conferencia "Ética y moral", recogida en C. Gómez, (2002a), pp. 241-255. 
Dicen que quien va a morir recorre toda su vida en un instante, o lo que entonces se le aparecen como los momentos más significativos de ella y que le prestan sentido y unidad. Quizá aquí sucede lo que en la experiencia psicoanalítica, en donde no se trata de repasar todos y cada uno de los momentos vividos (lo que exigiría otra vida igual de larga, al menos, y ya es suficientemente amplio un psicoanálisis como para recargarle con ese peso), sino aquellos acontecimientos significativos (recordados u ocultos), que permiten, de tiempo en tiempo, y con los mismos elementos, reordenar el psiquismo, como si de estratos geológicos se tratase, de acuerdo con lo que ya observó desde un punto de vista estilístico Pascal: "No se diga que he dicho lo mismo, porque las mismas palabras, por la fuerza de una disposición distinta, forman el cuerpo de un discurso diferente" (Pascal, 1962, 22).

De todos modos, la experiencia de la muerte ajena suele ser muy superficial o muy distante. Y antes de la muerte, a la que luego habremos de volver, Kierkegaard entendió precisamente el "instante" como la tangencia de lo temporal y lo eterno, como si de golpe el hombre pudiera, en medio de su historia, divisar la eternidad y en vez de extraviarse en los mil vericuetos de la vida darse cuenta de la seriedad de su existencia y "elegirse". Para Kierkegaard el hombre se constituye a través de sus elecciones -tema que herederá el existencialismo posterior, por diverso que sea su signo-, pues vivir es elegir, elegirse, y quien no lo hace ya ha elegido no elegir o deja que otros, la sociedad y las circunstancias vayan eligiendo por él, lo cual es también, sí, una elección, pero en sentido impropio. El hombre del estadio estético (Kierkegaard, 1951) es el que realiza sus elecciones desde una cierta indiferencia. Se elige ahora esto, luego lo otro, sin que en ninguna de esas elecciones el hombre comprometa su existencia, mariposeando entre las diversas posibilidades que la vida le ofrece, como se ejemplifica ante todo en el mito de Don Juan. La diferencia radical entre el hombre del estadio estético y el del estadio ético no es que uno elija el mal y el otro el bien, sino que el primero no quiere hacerse cargo de la cuestión, mientras que el segundo la tiene en cuenta. Y por eso en el elegir se trata de elegir bien, pero ante todo de la energía, la seriedad, el pathos con el que se elige: "La elección misma es decisiva para el contenido de la personalidad; con la elección se hunde ella en lo elegido, y si no elige, se marchita en su propia consunción"(Kierkegaard, 1943, p. 469). El hombre se desvive entonces, pero no en el sentido de que despliegue sus posibilidades y alcance así una "arrebatadora plenitud", sino malgastando su vida en cualquier secreto extravío, por el que se diluye como sombra entre las sombras mucho antes de morir.

El instante es entonces el momento de la conversión. Religiosa o ética, o ético-religiosa, toda conversión tiene lugar, como la de san Pablo camino de Damasco, en un "instante", aunque ese instante haya venido precedido por una larga lucha, a veces de años. En sus Variedades de la experiencia religiosa (James, 2002), un libro hoy un tanto olvidado, pero que despertó el interés de Unamuno y al que recientemente ha apelado Charles Taylor en A Secular Age (Taylor, 2007), James describió algunas experiencias excepcionales de los "nacidos dos veces", esto es, aquéllos que, tras pasar por los laberintos del mal, decidían orientar su vida en otro sentido y nacían de nuevo, aunque ese nuevo nacimiento hubiera tenido una larga gestación. Uno de los ejemplos cardinales en nuestra cultura, más allá de los acuerdos o desacuerdos que con este u otro aspecto de sus doctrinas se mantenga, es el de Agustín de Hipona, al que no en vano se ha considerado, por su descripción de la intimidad y la subjetividad, como "el primer moderno". Pero Agustín mismo se ha encargado de 
manifestarnos en sus Confesiones el combate interior al que se vio enfrentado, pues "es más fácil contar los cabellos del hombre que los sentimientos e impulsos de su corazón" (Agustín, $1990,107)$ y "así vine a ser una infeliz morada para mí mismo, donde ni podía estar ni de donde me era dado salir" (Ibíd., p. 100). "Decía yo dentro de mí: “Ahora mismo, que sea ahora mismo'. Mis deseos iban detrás de mis palabras. Ya casi lo hacía, pero no llegaba a hacerlo" (Ibíd., p. 221). "No tenía nada que responder más que palabras lentas como las del soñoliento: 'Ahora', 'voy', 'un poco más'. Pero este 'ahora' no tenía término y el 'poquito más’ se alargaba indefinidamente” (Ibíd., 209).

Por poner sólo un ejemplo esclarecedor, Agustín se refiere también a su amigo Alipio, quien creyéndose a salvo del placer de ver sufrir, torturar y morir a otros se dejó arrastrar por unos compañeros a un espectáculo de lucha entre gladiadores, pensando que, cerrando los ojos, estaría allí como si no estuviera. Más le hubiera valido cerrar también los oídos, pues, en un momento el rugido de placer de la multitud

fue tan grande y vehemente que -vencido de la curiosidad y muy confiado de que viera lo que viera era lo suficientemente fuerte para superarlo-, abrió los ojos. La herida que recibió en su alma fue más grave que la que había recibido el gladiador en el cuerpo y cayó más miserablemente que el otro a quien deseó ver caer [...]. Porque tan pronto como vio la sangre corriendo, bebió la crueldad y no apartó los ojos. Antes se puso a mirar muy atento y se enfureció sin darse cuenta deleitándose con la maldad de aquella pelea y embriagándose con aquel sangriento placer (Ibíd., p. 154).

José Luis Aranguren se refirió en su Ética (Aranguren, 2001, pp. 141-147; en O. C., II, pp. 310-316) al instante kierkegaardiano, al que consideraba, junto a la "repetición" y el "siempre" (que aquí no vamos a considerar), "actos privilegiados", definitorios de la vida, junto a los que la muerte se manifiesta no sólo como acto definitorio, sino también definitivo. En efecto, hasta la hora de la muerte hay tiempo de orientarnos de un modo u otro, pero después todo queda sellado y de ahí el carácter de recapitulación, de repetición reasuntiva, si es que se puede llegar a hacer.

Pero si la muerte de otros nos es muy ajena, según decíamos, la nuestra no puede ser vivida, hasta que llega y entonces, como quería Epicuro, nosotros no estamos. Claro que semejante estrategia de extraterritorialización no creo que haya aportado consuelo a nadie en modo alguno pues, como también se ha dicho, "apenas hemos nacido y ya somos lo suficientemente viejos para morir" (Heidegger, 2003, p. 242), esto es, la muerte proyecta su sombra sobre toda la vida, pues no sólo morimos sino que también sabemos anticipadamente que hemos de morir, lo que nos hace mortales (Savater, 1999, pp. 29 y ss.). Lo único que podemos hacer es tratar de asumirla, hasta donde podamos, hacer anticipadamente el duelo por nosotros mismos, sin entregarnos por ello a la ampulosidad estoica de tratar de vivir cada día como si ése fuera el último, cosa un tanto imposible y estéril, frente a lo cual quizá sea más adecuado ir haciéndonos cargo de nuestro morir. Es verdad que la muerte, a veces jaleada o enaltecida, en otras ocasiones morbosamente considerada, la desterramos en general de nuestras vidas y la consideramos asunto de la casualidad ("si no hubiera tomado ese tren", "si me hubiera quedado acompañándole"...) o espectáculo (la muerte televisada 
de los accidentes o las catástrofes), como bien ha estudiado Ph. Ariès en El hombre ante la muerte (Ariès, 1992) y, más brevemente, en La muerte en Occidente (Ariès, 1982). En sus Consideraciones de actualidad sobre la guerra y la muerte (Freud, 1972b), Freud hacía notar que esa forma de considerarla no estaba sino al servicio de una ilusión (de una ilusión ilusoria, quería decir; no todas lo son, como hubo de conceder) y lo malo de esas ilusiones es que a veces chocan con un trozo de realidad y saltan hechas pedazos. Si alguna ventaja ha aportado la guerra (se refiere a la Gran Guerra, como se denominó a la de 1914-1918) es ponernos cara a cara frente a ella y obligarnos a aceptar que todos, en efecto, hemos de morir: son tantas balas, tantos cadáveres que ya no vale escudarse en la casualidad. Es cierto que en lo inconsciente, que no conoce la negación, todos nos consideramos inmortales. Pues aunque desde pequeños sepamos que vamos a morir, revestidos de narcisismo y omnipotencia, sobre todo en la juventud, no nos lo creemos y eso es lo que presta a veces una simulada heroicidad. La creencia en la muerte sólo empieza a asentarse en nosotros a través de la de personas queridas, con las que se nos van objetos de amor muy preciados y con cuya desaparición, a través de la identificación con ellas, la realidad nos arranca a nosotros mismos también un buen pedazo y nos va haciendo aceptar que todo, también nuestro amado yo, ha de morir.

Aunque pretendamos distraernos de ello, que la muerte es ineluctable es de las cosas más ciertas que tenemos y ha sido en ocasiones bellamente puesto de manifiesto. Piénsese en $E l$ séptimo sello de I. Bergman, por aludir a una obra cinematográfica, que sigue conservando su enorme fuerza expresiva. También ahí, la primera vez que el caballero se encuentra con la muerte, parece que, distraído en un quehacer, no puede atenderla y le dice: "Espera un momento", pero la muerte, inflexible, le responde: "Eso me piden todos". El caballero trata de ganarle la partida de ajedrez que entablan y, contento de encontrar una buena jugada que cree le pone a salvo, se lo comenta al confesor. Pero quien sale del confesionario es la muerte misma que se había colado en él y se aleja diciéndole: "Gracias". Así también en el cuento oriental, en el que un criado sale a pasear por el jardín del visir de Bagdad, se tropieza con la muerte y regresa aterrorizado pidiéndole a su señor que le deje ir a Samarra, para protegerse junto a su familia. El visir le deja marchar y sale él mismo a pasear por el jardín donde todavía se encuentra la muerte a la que le increpa: "No me gusta que mires amenazadoramente a mis criados". Pero la muerte le replica: "No le he mirado amenazándole. Le he mirado con sorpresa. Me ha sorprendido verle esta mañana en Bagdad, cuando tengo una cita con él esta noche en Samarra".

Pues bien, frente a ese carácter ineluctable que nos tratamos de ocultar, el consejo de Freud es hacernos cargo de ella, no para exaltarla, sino, antes al contrario, para que cuidemos mejor, mientras podamos, de la vida misma. Por eso propone cambiar el viejo adagio latino Si vis pacem, para bellum, "si quieres la paz, prepárate para la guerra", por otro que dijese: Si vis vitam, para mortem, "si quieres vivir, prepárate para morir".

Y de ese modo, y mientras podamos encargarnos de nuestro morir, antes de ser simplemente un residuo comatoso, preguntarnos por lo que hemos hecho con nosotros mismos y con nuestra vida, que es quizá la pregunta ética fundamental, que habremos de "repetir", reasuntiva, recapitulatoria y sopesadamente, cuando hayamos de despedirnos de ella. Si es que aún hemos de hacer caso a la advertencia socrática, según la cual "una vida no examinada no merece la pena de ser vivida" (Platón, 1985, 38a). 
Pues bien, si habíamos aproximado el relato y la vida gracias a la estructura prenarrativa de la vida misma y a nuestra identidad narrativa, ¿qué tipo de literatura podría ajustarse a la experiencia del "instante" que hemos venido comentando? No creo que nos equivoquemos mucho al pensar que el "género" literario por excelencia que puede acercarse a ella y expresarlo es la poesía. "Palabra en el tiempo", como la consideró Machado, quizá la definición más breve de la misma pudiera ser: "intensidad”. La poesía no puede leerse como una novela en la que, aunque a veces convenga volver sobre ellos, podemos pasar de un capítulo a otro y leer varios seguidos "de un tirón", como suele decirse y como nos apetece hacer con las obras que nos seducen y no nos dejan apartarnos de ellas. Pero con la poesía, a veces basta con un solo poema. Su intensidad impide seguir con otros mientras los resortes anímicos que ha despertado sigan vibrando. Sucede aquí, en buena medida, lo que con la música (quizá, junto a la poesía, la más apta para expresar el mundo emocional e incluso, si hacemos caso a Bloch, la más utópica de todas las artes), en la que, a no ser que la tengamos de sonsonete, no podemos pasar fácilmente de una a otra obra, si nos hemos "metido" en cualquiera de ellas. La audición de una sinfonía o de una sonata rompe de tal forma la costra de la vida cotidiana, que nos lleva a un mundo distinto (pero no necesariamente meramente evasivo: su promesse de bonheur, su promesa de felicidad, en la fórmula de Stendhal reasumida por los frankfurtianos, puede revertir críticamente sobre el presente) e incluso al ámbito de lo sagrado, si, como querían Adorno y Horkheimer en su Dialéctica de la Ilustración, "el arte aspira a la dignidad de lo Absoluto" (Adorno y Horkheimer, 1994, p. 73). Y como observaba Elíade respecto al ámbito religioso, el mundo de lo sagrado muestra tal fecundidad y valor, que quisiéramos prolongar del modo más fructífero posible nuestro contacto con él, percibiendo que ahí se encuentra algo profundo y quizá lo más humano. Pero es de tal intensidad, sobrepasa de tal modo nuestra existencia histórica y temporal, que también es más que humano e, incapaces de permanecer ahí, hemos de caer desde ese ámbito al mundo de lo profano y lo cotidiano, que también tiene su valor, aunque se juega en otro plano (Eliade, 1981, p. 41). "Quien ve a Dios muere" se lee en la Biblia. Y también, en referencia al arte, decía Rainer María Rilke que "la belleza está en el límite de lo que podemos soportar". Queremos llegar a ella, pero sobre ella se cierne la amenaza de lo espantoso, según recuerda el libro de Trías Lo bello y lo siniestro (Trías, 1988), en donde se persigue y enlaza el análisis kantiano de lo bello y lo sublime en la Crítica del juicio con el artículo de Freud sobre Lo siniestro.

El poeta rompe la costra de lo trillado y consabido. Pero para ello no necesita ir a un mundo especial, lleno de misterios, sino que se asombra ante el misterio del mundo mismo al contemplarlo de otro modo, desde lo que los fenomenólogos califican como "una ruptura de nivel". Por poner sólo un ejemplo, que tomo de La voz a ti debida de Salinas (Salinas, 1969), vean esos dos planos -sin detenernos en otros aspectos formales- en el siguiente breve poema:

Yo no necesito tiempo

para saber cómo eres:

conocerse es el relámpago.

¿Quién te va a ti a conocer

en lo que callas, o en esas 
palabras con que lo callas? El que te busque en la vida que estás viviendo, no sabe más que alusiones de ti, pretextos donde te escondes. [...]. Yo no.

Te conocí en la tormenta.

Te conocí, repentina, en ese desgarramiento brutal de tiniebla y luz, donde se revela el fondo que escapa al día y la noche. Te vi, me has visto, y ahora, desnuda ya del equívoco, de la historia, del pasado, [...] eres tan antigua mía, te conozco tan de tiempo, que en tu amor cierro los ojos, y camino sin errar, a ciegas, sin pedir nada a esa luz lenta y segura con que se conocen letras y formas y se echan cuentas $\mathrm{y}$ se cree que se ve quién eres tú, mi invisible 5 .

La luz lenta y segura de lo cotidiano frente al fondo que escapa al día y la noche, donde se puede caminar a ciegas, sin errar, y ver lo invisible.

El propio Aranguren ha dedicado varios de sus escritos literarios a algunos de los mejores poemas de nuestra lengua. Y tal vez, ante todo, a los de San Juan de la Cruz, al que volvió nada menos que en tres ocasiones: en una primera compuso todo un libro sobre él, un extracto del cual figura como amplia "Introducción" a la edición Vergara de San Juan de la Cruz (Juan de la Cruz, 1965). Tras la expulsión de su cátedra por el régimen franquista, en 1971 dio un curso sobre él en la Universidad de California, Santa Bárbara. Finalmente, tenemos el texto al que ahora nos vamos a referir.

Prescindiendo de otros aspectos, Aranguren propone ante todo hacer de esos poemas una lectura "exenta", es decir no prejudicada por la resonancia teológica que tienen y que el propio autor quería darles. Si procedemos así, lo que ante todo resalta en el Cántico espiritual, es que estamos ante un poema altamente erótico. En comparación con algunos de los modelos que San Juan siguió, como fue sin duda el bíblico Cantar de los Cantares, ya en la estructura formal contrasta el carácter intimista del Cántico con la apertura ceremonial,

5 Cursivas mías. 
comunitaria, de la celebración de los amores del rey en el Cantar. Sobre todo, el carácter sensual del Cantar y su índole estática se contraponen al dramatismo erótico del Cántico.

El Cantar-que, retengamos esto, canta un matrimonio consumado ya- es un poema oriental, lleno de sensualidad: perfumes de las más diversas especies, la naturaleza en toda su voluptuosidad, los ojos, los cabellos, los labios, el cuello de la esposa, sus senos, su vientre, su ombligo, también los encantos de su esposo, y el vino y los aromas de las plantas, la leche y la miel, los cedros y los cipreses, las tórtolas y las palomas [...]. A la vez, la sensación que nos da la lectura es puramente plástica, como la de visión de un espléndido cuadro, sensación estática [...]. En el poema -quizá por no ser tal poema sino un conjunto de poemas cuasi-repetitivos- no pasa nada, no hay apenas acción [...]. En contraste con el Cantar, el Cántico [...] no un «cuadro plástico», sino un acontecimiento dramático [...]. La «acción» del Cántico es la consumación de la unión amorosa, enteramente narrada. Lo que digo es que en el Cántico asistimos -lo que no es el caso de los otros dos poemas [Noche oscura y Llama de amor viva], ni tampoco del Cantar de los cantares- al acto mismo de la unión de los amantes. El Cantar de los cantares era poema sobrecargadamente sensual. El Cántico no es sensual, pero es en cambio profundamente erótico. En otro lugar ${ }^{6}$ he escrito sobre la «mística» intrínseca al hecho erótico (que, dicho sea por ahora entre paréntesis, es lo que ha hecho no sólo posible sino inevitable que la imagen por excelencia de la unio mystica sea la unión erótica). A través del sexo y de la comunicación sexual, vivida en toda su hondura, hay una búsqueda, un afán de Absoluto, de trascendencia del finito yo y, en sentido amplio, de religiosidad mística (Aranguren, 1973b, pp. 268-271; cf. asimismo Gómez, 2010, pp. 274-275).

Un poema erótico, pero, por supuesto, como el propio Aranguren advierte, no pornográfico ${ }^{7}$ : el proceso hacia la unión y la consumación están expresados indirectamente; es al movimiento del verso y al tempo del poema a los que se confía la «descripción» del acto. Muy claramente, podríamos añadir, en dos ocasiones, una casi al comienzo del poema y otra más bien al final. En una y otra ocasión, la tensión hacia la unión da paso, es forzoso suponer que después de ella, a la complacencia entre los amantes y con la Naturaleza. La primera vez, tras

Descubre tu presencia,

Y máteme tu vista y hermosura...

Se lee:

Mi Amado, las montañas,

los valles solitarios nemorosos...

6 Aranguren se refiere a Erotismo y liberación de la mujer, 1973a.

7 Al erotismo, la pornografía y la abolición de la identidad se había referido en Sobre imagen, identidad y heterodoxia, 1982. 
Hacia el final del poema, tras "gocémonos, Amado, / y vámonos a ver en tu hermosura":
Allí me mostrarías
aquello que mi alma pretendía,
y luego me darías
allí tú, vida mía,
aquello que me diste el otro día:

Y de nuevo:

El aspirar del aire,

el canto de la dulce filomena...

Esta relación entre éxtasis erótico y éxtasis místico ha sido puesta de relieve en muchas ocasiones. Pues la relación sexual puede tener muchas manifestaciones y modos de vivirse, desde el lado que la decanta hacia la objetualización del otro a ser quizá la máxima forma de comunicación y patencia de una persona a otra, que, con todo, quizá nos lleve más allá. De ahí el asombro ante la facilidad con que muchos pretenden estar de vuelta de ella -incluidos los adolescentes de nuestro tiempo, cuando apenas han podido abrirse a ella... - . Frente a tal actitud, alguien como Freud, que se consagró a su estudio, todavía manifestaba al final de su vida que le seguía pareciendo "un enigma" (Freud, Análisis terminable e interminable, 1972c). Y es ese carácter enigmático, además de otros aspectos ya considerados, el que facilita la comparación con la mística (también cabe compararla, por supuesto, con la pseudomística, como hacía Flaubert en Madame Bovary ${ }^{8}$ ) y que se hable para referirse a la culminación de la experiencia sexual de "trance" y de "éxtasis", a la vez que la mística ha echado mano siempre de símbolos eróticos. Una y otra se refieren al instante del que veníamos hablando. Pero yo quisiera, para encaminarnos hacia la conclusión, retomar el carácter narrativo con el que iniciábamos esta exposición.

En efecto, como el propio Aranguren recuerda, la vida erótica, en lo que tenga de mística, y la vida mística misma son mística del Instante. Pero esta dimensión, o no-dimensión del punto de tiempo que es el instante sitúa a los protagonistas fuera del tiempo. Al menos mientras dura tal experiencia, si bien la mística no suele separar totalmente el instante de la existencia -en cuanto culminación de un proceso ascético que se realiza a lo largo de la vida- y en lo erótico, pese a la confianza que se tenga en que puede llenar toda una vida, ésta lo desborda ya que también consiste en otras cosas; lo erótico, por importante que sea,

8 Los hombres profundamente religiosos y los místicos han recelado siempre de arrobamientos y trances, pues, para decirlo ahora con Pascal, nada se parece más al amor a Dios que el afán irrefrenable de querer incorporarlo todo a sí, que es su opuesto. En el caso de Emma Bovary, insatisfecha con su marido y desengañada asimismo de sus diversos amantes (pues "Emma volvía a encontrar en el adulterio todas las soserías del matrimonio", Flaubert, 1993, p. 353), así como de sus lecturas o sus labores (todas las cuales "una vez comenzadas, iban a parar al armario; las tomaba, las dejaba, pasaba a otras", p. 199), ansiosa de pasión y felicidad, todo la hartaba. Hasta que un buen día reparó en que en existía un amor por encima de todos los amores, sin intermitencia ni fin. Y anota Flaubert: "Quiso ser una santa, se compró un rosario, se puso amuletos [...]. Cuando se arrodillaba en su reclinatorio gótico le murmuraba a Dios las mismas palabras de dulzura que antes a sus amantes, en los desahogos del adulterio" (pp. 281-282). 
no abarca la totalidad de lo real. Y quizá aquí es donde tenga cabida el amor, que permite referir el éxtasis del presente al resto de la realidad y a la procesualidad de la vida.

Llegados a este punto, es donde quisiera hacer ingresar en nuestros análisis -entrando así sin ruido, como de puntillas- la palabra amor, escrita con minúscula. Dentro de este proceso en que consiste la vida, amor significaría sencillamente el esfuerzo por mantener lo erótico unido a la realidad, en continuidad con dicha realidad. Lo que aportaría el amor, frente al Presente o Instante, sería la vivencia del tiempo como continuidad; serían el pasado y el futuro puestos en relación con el éxtasis del presente, sería la vida entera vivida en continuidad y con responsabilidad. Entiendo la palabra responsabilidad en el sentido de que lo erótico, en cuanto que aislado y convertido en puramente místico, sería irresponsable, no en la acepción obviamente peyorativa de la palabra, sino en la de que no es capaz de dar respuesta, de que es una especie de grito, de gemido, de exclamación; en tanto que responsabilidad es actitud articulada y firme a lo largo de la vida. En suma, lo que el amor aportaría al erotismo es la dimensión cronológica, sostenida, diacrónica (Aranguren, 1973b, pp. 279-280).

Con esto retornamos, entonces, a la vida como proceso de la que comenzamos y hemos venido hablando

\section{Los textos vivos y la comprensión de sí}

Al volver de nuevo a la vida como un texto, podemos hacer notar, si aún hiciera falta y como al principio anuncié, la cercanía de algunas formulaciones de Aranguren a las ya consideradas en Ricoeur. Y para ello, nada mejor quizá que traer a colación la hermosa metáfora de los "textos vivos", a la que en diversas ocasiones se refirió. La expresión procede de un episodio de nuestra historia universitaria, la separación de los profesores krausistas del siglo diecinueve de sus cátedras. El krausismo, inspirado en Friedrich Krause, fue difundido especialmente en España a través de la labor de Julián Sanz del Río y más tarde de Francisco Giner de los Ríos, fundador de la Institución Libre de Enseñanza. Expurgados por la autoridad académica los "libros de texto" se pensó que ello no era suficiente y que debía acompañarse de la expulsión de los "textos vivos", como se dio en llamar a los citados profesores, sentando un precedente que acabaría asimismo por afectar, años más tarde, al propio Aranguren. Comentando ese episodio, pero remontándose a una reflexión más general, observa:

Pero lo cierto es que todos y cada uno de nosotros somos eso, textos vivos. Textos que nuestro «yo reflexivo» va, por así decirlo, escribiendo, contándose a sí mismo, con más o menos tino, al hilo de la vida protagonizada por nuestro «yo ejecutivo». Contar es como vivir y vivir es como contar o, mejor dicho, contarse, de manera que el mundo vivido y el narrado se solapan inevitablemente. Somos o, al menos, nos figuramos ser nuestra propia novela, la «narración narrante» de nuestra vida. Y, como los textos literarios, también los textos que somos requieren de interpretación, razón por la que todos aventuramos, clara o confusamente, nuestra propia hermenéutica. 
Y agregando a esa relación entre literatura y vida una estremecida esperanza religiosa, concluye:

Como también cabe de ellos la exégesis que hagan los demás, si la llegan a hacer, cuando el relato se dé por concluido y nos toque, después de nosotros mismos, la hora de su «comprensión». ¿A quién pedir esa última comprensión que consista no tanto en juzgarnos cuanto en decirnos quiénes somos, quién soy? No sé, tal vez a la Deidad ante la cual hayamos existido, siquiera como sueño, de suerte que, si «la vida es sueño», sea, haya sido, esté siendo, vaya a ser sueño «de» Dios. Pero ya digo que no sé.

Dejemos aquí, con esta estremecida esperanza, a Aranguren, para, en una muy breve reflexión final, plantear una sugerencia antropológica. El pie me viene dado por el último texto en el que se hacía referencia a la pregunta ¿quién soy? Como se sabe, ésa era para Kant la pregunta filosófica fundamental en la que se compendiaban las otras tres grandes preguntas en las que confluyen para él todos los intereses de la razón: ¿qué puedo conocer?, ¿qué debo hacer?, ¿qué podemos esperar? Que el hombre sea un ser que se interrogue sobre sí mismo es ya digno de reflexión, pues como observara Dostoievski, la hormiga conoce el molde de su hormiguero, la abeja conoce el molde de su panal. El hombre es el único ser que no conoce su propio molde.

En cualquier caso, y sin osar ahora introducirme en tan apasionante pero arduo terreno, y sólo como sugerencia según decía, quizá lo que nos pueda hacer justicia sea no esquivar la pregunta -que a veces nos ilusiona pero también nos desasosiega, por lo que en tantas ocasiones nos conformamos con las identidades que externamente nos vienen dadas, por los papeles o atributos sociales a los que se refería Robert Musil (Musil, 2001)- pero tampoco permanecer en la nuda interrogación que nos deja sin amarres ni arrimos, continuamente a la intemperie, lo que me temo sólo serviría, más pronto que tarde, para acabar buscando refugio en cualquier covacha. Incapaces de eludirla, pero incapaces de responderla, dado que el hombre, según hemos insistido, no está nunca dado de una vez sino que siempre se encuentra in fieri, haciéndose, quizá lo más que podamos encontrar, entre la desnudez esteparia del puro interrogante y el señuelo de hallar el verdadero rostro, la morada definitiva, sea algo así como albergue provisional, posada en el tiempo. Esa posada en el tiempo que haría consonancia con la identidad narrativa de la que hemos venido hablando.

\section{Referencias}

Adorno, Th. W. y Horkheimer, M. (1994): Dialéctica de la Ilustración, trad. de J. J. Sánchez, Madrid, Trotta.

Agustín, san (1990): Confesiones, ed. de P. Rodríguez de Santidrián, Madrid, Alianza.

Aranguren, J. L. L. (1973a): Erotismo y liberación de la mujer, en O. C., cit., III, 583-650.

Aranguren, J. L. L. (1973b): "San Juan de la Cruz", en O. C., cit., VI, pp. 268-281.

Aranguren, J. L. L. (1982): Sobre imagen, identidad y heterodoxia, en O. C., cit., T. III 
Aranguren, J. L. L. (1993): Estudios literarios, Madrid, Círculo de lectores, ed. ampliada. (Recogido asimismo en el vol. 6 de las Obras completas, 1994-1996).

Aranguren, J. L. L. (1994-1996): Obras completas, ed. de F. Blázquez, Madrid, Trotta, 6 vols. Aranguren, J. J. L. (1996): "El teatro y la vida", en Obras Completas, cit., VI, 335-337. (Recogido asimismo en Gómez, 2010, pp. 278-280).

Aranguren, J. L. L. (2001); Ética, Madrid, Alianza, 9ª reimp. (Se encuentra asimismo en Obras Completas, cit, T. II).

Ariès, Ph. (1982): La muerte en Occidente, trad. J. Elías, Barcelona, Argos Vergara.

Ariès, Ph. (1992): El hombre ante la muerte, trad. M. Armiño, Madrid, Taurus, $4^{\mathrm{a}}$ ed.

Aristóteles (1974), Poética, edición trilingüe de V. García Yebra, Madrid, Gredos.

Eliade, M. (1981): Tratado de historia de las religiones. Morfología y dinámica de lo sagrado, trad. de A. Medinaveitia, Madrid, Cristiandad, $2^{\mathrm{a}} \mathrm{ed.}$

Flaubert, G. (1993): Madame Bovary, trad. de G. Palacios, Madrid, Cátedra, $5^{\mathrm{a}}$ ed.

Freud, S. (1972a): La interpretación de los sueños, en Obras Completas, trad. de L. LópezBallesteros y de Torres, Madrid, Biblioteca Nueva, $3^{\text {a }}$ ed., T. I

Freud, S. (1972b): Consideraciones de actualidad sobre la guerra y la muerte, en O.C., cit., T. II.

Freud, S. (1972c): Análisis terminable e interminable, en O. C., cit., T. III.

Gómez, C. (1995): "La Escuela de Frankfurt: Jürgen Habermas”, en F. Vallespín, ed. (1995), Historia de la Teoría Política. VI, Madrid, Alianza, pp. 219-258.

Gómez, C. (2002a): Doce textos fundamentales de la ética del siglo XX, Madrid, Alianza, $5^{\text {a }}$ reimp. 2012.

Gómez, C. (2002b): Freud y su obra. Génesis y constitución de la Teoría Psicoanalítica, Madrid, biblioteca Nueva-Asociación Psicoanalítica de Madrid, 2ª ed. 2009.

Gómez, C. (2010a): José Luis L. Aranguren. Filosofía y vida intelectual. Textos fundamentales, Madrid, Trotta-UNED.

Gómez, C. (2010b): "Razón de la sinrazón de los sueños", prólogo a S. Freud, La interpretación de los sueños, trad. de L. López Ballesteros y de Torres, Madrid, Ediciones El País, pp. 9-20.

González, J. Mª (1998): Metáforas del poder, Madrid, Alianza.

González, J. Ma (2006): La diosa Fortuna. Metamorfosis de una metáfora política, Madrid, Antonio Machado.

Habermas, J. (1985): "Ética del discurso, Notas sobre un programa de fundamentación", en Conciencia moral y acción comunicativa, trad. de R. García Cotarelo, Barcelona, Península, 57-134.

Heidegger, M. (2003): Ser y tiempo, trad. de J. E. Rivera, Madrid, Trotta.

James, W. (2002): Las variedades de la experiencia religiosa, trad. de J.-F. Ivars, Barcelona, Península.

Juan de la Cruz, san (1965): Obras, ed. de J. L. L. Aranguren, Barcelona, Vergara.

Kierkegaard, S. (1943): Ou bien...ou bien, trad. del danés por F. y O. Prior y M. H. Guignot, París, Gallimard. (Hay ed. en castellano, de B. Sáez Tajafuerte, La alternativa, en Madrid, Trotta, 2006).

Kierkegaard, S. (1951): Etapas en el camino de la vida, trad. de J. Rueda, Buenos Aires, Santiago Rueda. 
López de la Vieja, Ma T. (2003): Ética y Literatura, Madrid, Tecnos.

López de la Vieja (2013): Bioética y Literatura, Madrid, Plaza y Valdés.

Mayorga, J. (2013): La lengua en pedazos, Buenos Aires, CELCIT

Mayorga, J. (2014): Teatro, 1989-2014, prólogo de Claire Spooner, Segovia, La uña rota ediciones.

Martín Díez Fischer, F. (2014): "La potencialidad de la tradición hermenéutica”, Doletiana, 4, pp. 1-10.

Musil, R. (2001): El hombre sin atributos, trad. J. Ma Sáenz, Barcelona, Seix Barral

Ortega y Gasset, J. (1970): Historia como sistema, Madrid, Revista de Occidente, $6^{\mathrm{a}}$ ed.

Pascal, B. (1962): Pensamientos, trad. de X. Zubiri, Madrid, Espasa-Calpe, 6 a ed.

Pérez, J. (2007): Teresa de Ávila y la España de su tiempo; Madrid, Algaba.

Pirandello, L. (1999): Seis personajes en busca de autor, trad. M. Massa-Carrara, Madrid, Jorge A. Mestas ediciones.

Platón (1985): Apología de Sócrates, en Diálogos, I, introd. De E. Lledó, trad. de J. Calonge, Madrid, Gredos.

Ricoeur, P. (1988): El discurso de la acción, trad. de P. Calvo, Madrid, Cátedra, $2^{\mathrm{a}}$ ed.

Ricoeur, P. (1995-1996): Tiempo y narración, trad. A. Neira, Madrid, Siglo XXI. (3 vols.: I. Configuración del tiempo en el relato histórico, II. Configuración del tiempo en el relato de ficción, III. El tiempo narrado).

Ricoeur, P. (1996): Sí mismo como otro, trad. de A. Neira, Madrid, Siglo XXI.

Ricoeur, P. (2001): La metáfora viva, trad. de A. Neira, Madrid, Trotta, $2^{\mathrm{a}}$ ed.

Ricoeur, P. (2009): "La vida: un relato en busca de narrador", en Ricoeur, P., Escritos y conferencias, I. Alrededor del psicoanálisis, trad. de A. Castañón, México, Siglo XXI, pp. 192-206.

Salinas, P. (1969): La voz a ti debida. Razón de amor, ed. de J. González Muela, Madrid, Castalia.

Savater, F. (1990): “Comentario a Desde la perplejidad”, El País, 23 de septiembre.

Savater, F. (1999): Las preguntas de la vida, Barcelona, Ariel.

Taylor, Ch. (2007): A Secular Age, Harvard University Press. (La primera parte de la obra ha sido recientemente traducida como La edad secular, I, trad. de R. García Pérez, Barcelona, Gedisa, 2014).

Tirso de Molina (2008): El condenado por desconfiado, Madrid, Cátedra.

Thiebaut, C. (1995): "Filosofía y Literatura: de la retórica a la poética", Isegoría, 11 (1995), pp. 81-107.

Trías, E. (1988): Lo bello y lo siniestro, Barcelona, Ariel.

Trías, E. (2002): "La filosofía y su poética”, Archipiélago, 50, pp. 41-42. 
